\title{
Downregulated parafibromin expression is a promising marker for pathogenesis, invasion, metastasis and prognosis of gastric carcinomas
}

\author{
Hua-chuan Zheng • Hiroyuki Takahashi • Xiao-han Li • \\ Takuo Hara • Shinji Masuda • Yi-fu Guan • \\ Yasuo Takano
}

Received: 5 October 2007 / Revised: 9 November 2007 / Accepted: 10 November 2007 / Published online: 14 December 2007

(C) Springer-Verlag 2007

\begin{abstract}
Parafibromin is a protein encoded by the hyperparathyroidism 2 oncosuppressor gene and its downregulated expression is involved in pathogenesis of parathyroid carcinomas. To clarify the roles of parafibromin expression in tumourigenesis and progression of gastric carcinomas, it was examined by immunohistochemistry (IHC) on tissue microarray containing gastric carcinomas $(n=508)$, adenomas $(n=45)$ and gastritis $(n=49)$ with a comparison of its expression with clinicopathological parametres of carcinomas. Gastric carcinoma cell lines (MKN28, AGS, MKN45, KATO-III and HGC-27) were studied for parafibromin expression by IHC and western blot. Parafibromin expression was localised in the nucleus of gastric epithelial cells, adenoma, carcinoma cells and cell lines. Its expression was gradually decreased from gastritis to gastric carcinoma, through gastric adenomas $(p<0.05)$
\end{abstract}

H.-c. Zheng $(\bowtie) \cdot$ Y.-f. Guan

Department of Biochemistry and Molecular Biology,

College of Basic Medicine, China Medical University,

Shenyang, China

e-mail: zheng_huachuan@hotmail.com

H. Takahashi $\cdot$ Y. Takano

Department of Diagnostic Pathology,

Graduate School of Medicine and Pharmaceutical Sciences,

University of Toyama,

2630 Sugitani,

Toyama 930-0194, Japan

X.-h. Li

Division of Pathology,

Shenjing Hospital of China Medical University,

Shenyang, China

T. Hara $\cdot$ S. Masuda

Kouseiren Takaoka Hospital,

Takaoka, Japan and inversely correlated with tumour size, depth of invasion, lymphatic invasion, lymph node metastasis and Union Internationale Contre le Cancer (UICC) staging ( $p<$ $0.05)$ but not with sex or venous invasion $(p>0.05)$. Parafibromin was strongly expressed in older carcinoma patients compared with younger ones $(p<0.05)$. There was stronger positivity of parafibromin in intestinal-type than diffuse-type carcinomas $(p<0.05)$. Univariate analysis indicated cumulative survival rate of patients with positive parafibromin expression to be higher than without its expression $(p<0.05)$. Multivariate analysis showed that age, tumour size, depth of invasion, lymphatic invasion, lymph node metastasis, UICC staging and Lauren's classification but not sex, venous invasion or parafibromin expression were independent prognostic factors for carcinomas $(p<0.05)$. Downregulated parafibromin expression possibly contributed to pathogenesis, growth, invasion and metastasis of gastric carcinomas. It was considered as a promising marker to indicate the aggressive behaviours and prognosis of gastric carcinomas.

Keywords Gastric carcinoma · Parafibromin . Pathogenesis $\cdot$ Progression $\cdot$ Prognosis

\section{Introduction}

Parafibromin is a protein encoded by the hyperparathyroidism 2 (HRPT2) oncosuppressor gene, whose mutation causes the hyperparathyroidism-jaw tumour syndrome. The disease is an autosomal dominant disorder characterised by the occurrence of parathyroid adenoma or carcinoma, fibro-osseous jaw tumours of the mandible or maxilla and renal neoplastic and non-neoplastic abnormalities, such as Wilms' tumour, hamar- 
toma or cystic renal disease $[1,16,20]$. HRPT2 gene is located in human chromosome 1q31.2, consists of 17 exons and spans $18.5 \mathrm{~kb}$ in the genome. It encodes a $2.7-\mathrm{kb}$ transcript which is translated into a 531-amino-acid parafibromin protein with a molecular weight of $60 \mathrm{kd} \mathrm{[3,} \mathrm{4,} \mathrm{23].}$ The 200-amino-acid C-terminal segment of parafibromin shares $32 \%$ identity and 54\% homology with cell division cycle 73, a Saccharomyces cerevisiae protein forming the polymerase-associated factor 1 (Pafl) complex, which is associated with ribonucleic acid (RNA) polymerase II and involved in transcript site selection, transcriptional elongation, histone $\mathrm{H} 2 \mathrm{~B}$ ubiquitination, histone $\mathrm{H} 3$ methylation, poly (A) length control and coupling of transcriptional and posttranscriptional events [10, 17, 18, 24, 27]. Parafibromin overexpression was documented to inhibit colony formation and cellular proliferation and induce cell cycle arrest in the G1 phase, indicating that parafibromin has a critical role in cell growth [28]. Northern blot analysis showed HRPT2 expression in heart, brain, placenta, lung, liver, skeletal muscle, kidney and pancreas [4]. Western blot study revealed parafibromin expression as a $60-\mathrm{kd}$ band in the adrenal gland, heart, pancreas and kidney but 40-kd immunoreactive bands in the heart and skeletal muscle of human [25]. Immunohistochemically, higher expression of parafibromin was found widespread in glomerular mesangial cell, hepatocytes, cells of the base of gastric glands, renal cortex tubules and the pars intermedia of the hypophysis [17]. Subsequent investigations have revealed that mutations in HRPT2 are present in $66-100 \%$ of sporadic parathyroid carcinomas [7, 20]. Hyperparathyroidism-jaw-tumourssyndrome-related and sporadic parathyroid carcinomas are characterised by loss of parafibromin nuclear immunoreactivity [5, 22]. Selvarajan et al. [19] found that parafibromin expression was inversely linked to tumour size, pathologic stage and lymphovascular invasion of breast carcinomas using immunohistochemistry in a tissue microarray (TMA) study. These findings suggested the potential roles of parafibromin in pathogenesis and progression of malignancies.

Gastric carcinoma ranks as the world's second leading cause of cancer mortality behind lung cancer despite a sharp worldwide decline in both its incidence and mortality since the second half of the 20th century [9]. Tumourigenesis and progression of gastric carcinoma is a multistage process with the involvement of a multifactorial aetiology, which mainly results from gene-environment interactions $[32,33]$. Gastric carcinomas are classified into early and advanced ones on the basis of whether the carcinomas invade into the muscularis propria of the stomach [12]. In 1965, Lauren [13] classified gastric carcinomas into intestinal- and diffuse-type ones based on the morphological appearances. Intestinal-type carcinomas are characterised by cohesive carcinoma cells forming gland-like tubular structures with expanding or infiltrative growth pattern.
However, the cell cohesion is less apparent or absent in diffuse-type carcinoma and cancer cells diffusely spread in the gastric wall [31]. Generally, there is a favorable prognosis for the patients with early or intestinal carcinoma compared with the other type. In our study, parafibromin expression was examined in gastric carcinoma, adenoma, gastritis and gastric carcinoma cell lines and compared with the clinicopathological parametres of carcinomas, as well as prognosis to explore the clinicopathological significance and molecular roles of parafibromin expression in stepwise development of gastric carcinoma.

\section{Materials and methods}

\section{Subjects}

Gastric carcinomas $(n=508)$ were collected from the surgical resection, adenoma $(n=45)$ from endoscopic biopsy or polypectomy and gastritis $(n=49)$ from the endoscopic biopsy in our affiliated hospital, Himi Citizen Hospital and Kouseiren Takanoka Hospital between 1993 and 2006. All carcinomas were adenocarcinomas and the adenoma group was free from non-neoplastic polyp types, leiomyomas and benign gastrointestinal stromal tumours. The patients with gastric carcinoma were 354 men and 154 women (29 91 years, mean $=65.4$ years). Among them, 191 cases have carcinomas accompanied with lymph node metastasis. None of the patients underwent chemotherapy or radiotherapy before surgery. They all provided consent for use of tumour tissue for clinical research and our University Ethical Committee approved the research protocol. We followed up all patients by consulting their case documents or through telephone.

Pathology

All tissues were fixed in $4 \%$ neutralised formaldehyde, embedded in paraffin and incised into $4-\mu \mathrm{m}$ sections. These sections were stained by haematoxylin and eosin (HE) to confirm their histological diagnosis and other microscopic characteristics. The staging for each gastric carcinoma was evaluated according to the Union Internationale Contre le Cancer (UICC) system for the extent of tumour spread [21]. Histological architecture of gastric carcinoma was expressed in terms of Lauren's [13, 31] classification. Furthermore, tumour size, depth of invasion, lymphatic and venous invasion were determined.

Tissue microarray

Representative areas of solid tumours were identified in HEstained sections of the selected tumour cases and a 2-mm-in- 
diametre tissue core per donor block was punched out and transferred to a recipient block with a maximum of 48 cores using a Tissue Microarrayer (AZUMAYA KIN-1, Japan). Four-micrometre-thick sections were consecutively incised from the recipient block and transferred to polylysine-coated glass slides. HE staining was performed on TMA for confirmation of tumour tissue.

Cell lines and culture

Gastric carcinoma cell lines come from the Japanese Physical and Chemical Institute, including MKN28 (welldifferentiated adenocarcinoma), AGS (moderately differentiated adenocarcinoma), MNK45 (poorly differentiated adenocarcinoma), KATO-III (poorly differentiated adenocarcinoma) and HGC-27 (undifferentiated adenocarcinoma). They were maintained in Roswell Park Memorial Institute 1640 (MKN28, MKN45 and KATO-III), minimum essential (HGC-27) or Ham's F12 (AGS) medium supplemented with $10 \%$ foetal bovine serum, 100-units $/ \mathrm{ml}$ penicillin, and $100-\mu \mathrm{g} / \mathrm{ml}$ streptomycin in a humidified atmosphere of $5 \% \mathrm{CO}_{2}$ at $37^{\circ} \mathrm{C}$. Total protein was prepared from all cells by cell disruption buffer according to Protein And RNA Isolation System manual (Arctiris Bioscience, USA). All cells were collected by centrifugation, rinsed with phosphate-buffered saline, fixed by $10 \%$ formalin and then embedded in paraffin as routinely processed.

\section{Immunohistochemistry}

Consecutive sections were deparaffinised with xylene, dehydrated with alcohol and subjected to antigen retrieval by irradiating in target retrieval solution citrate $\mathrm{pH} \quad 6.0$ (TRS, DAKO, Carpinteria, CA 93013, USA) for $15 \mathrm{~min}$ with microwave oven (Oriental Rotor Lmt. Co., Tokyo, Japan). Five percent bovine serum albumin was then applied for $1 \mathrm{~min}$ to prevent non-specific binding. The sections were incubated with mouse anti-parafibromin antibody (Clone 2H1, SC-33638, Santa Cruz, CA, USA; $1: 40)$ for $15 \mathrm{~min}$, then treated with the anti-mouse EnvisonPO (DAKO, CA, USA) antibody for $15 \mathrm{~min}$. Binding sites were visualised with 3, 3'-diaminobenzidine with the 5-min reaction. All the incubations were performed in a microwave oven to allow intermittent irradiation as described previously [11]. After each treatment, the slides were washed with Tris-buffered saline with Tween 20 (TBST; $10 \mathrm{mM}$ Tris- $\mathrm{HCl}, 150 \mathrm{mM} \mathrm{NaCl}, 0.1 \%$ Tween 20) three times for $1 \mathrm{~min}$. After being counterstained with Mayer's haematoxylin, the sections were dehydrated, cleared and mounted. Omission of the primary antibody was used as a negative control.

One hundred cells were randomly selected and counted from five representative fields of each section blindly by three independent observers (Takano Y, Li XH and Zheng HC). The positive percentage of counted cells was graded semi-quantitatively according to a four-tier scoring system: negative $(-)$, 0 5\%; weakly positive $(+), 6 \sim 25 \%$; moderately positive $(++), 26 \sim 50 \%$; and strongly positive $(+++)$, $51 \sim 100 \%$.

\section{Western blot}

Fifty-microgramme denatured protein was separated on an SDS-polyacrylamide gel (10\% acrylamide) and transferred to Hybond membrane (Amersham, Germany), which was then blocked overnight in 5\% milk in TBST. For immunoblotting, the membrane was incubated for $1 \mathrm{~h}$ with mouse anti-parafibromin antibody as described above. Then, it was rinsed by TBST and incubated with antimouse immunoglobulin $\mathrm{G}$ conjugated to horseradish peroxidase (DAKO, CA, USA, 1:1,000) for $1 \mathrm{~h}$. Bands were visualised with X-ray film (Fujifilm, Japan) by ECL-Plus detection reagents (Amersham, Germany). After that, membrane was washed with WB Stripping Solution $(\mathrm{pH}$ 2-3, Nacalai, Tokyo, Japan) for $30 \mathrm{~min}$ and treated as described above except mouse anti- $\beta$-actin antibody (Sigma, MO, USA, 1:5,000) as an internal control.

\section{Statistical analysis}

Statistical evaluation was performed using Spearman correlation test to analyse the rank data. Kaplan-Meier survival plots were generated and comparisons between survival curves were made with the log-rank statistic. The Cox's proportional hazards model was employed for multivariate analysis. $P<0.05$ was considered as statistically significant. SPSS 10.0 software was employed to analyse all data.

\section{Results}

Parafibromin expression in gastric tumours and carcinoma cell lines

As shown in Fig. 1, parafibromin was positively immunostained in the nucleus of MKN28, AGS, MKN45, KATO-III and HGC-27, and its expression level was consistent with the data of Western blot. Parafibromin was strongly expressed in the nucleus of gastric epithelial cells, adenomas and early carcinomas but not in given advanced carcinomas. Occasionally, it also appeared in stromal fibroblasts and lymphocytes but much weaker than epithelial cells or adenomas (Fig. 2).Generally, the stromal lymphocytes and fibroblasts were negative in cases where the tumour was negative. Overall, parafibromin expression was detected respectively in all gastritis (100.0\%), 36 out of 

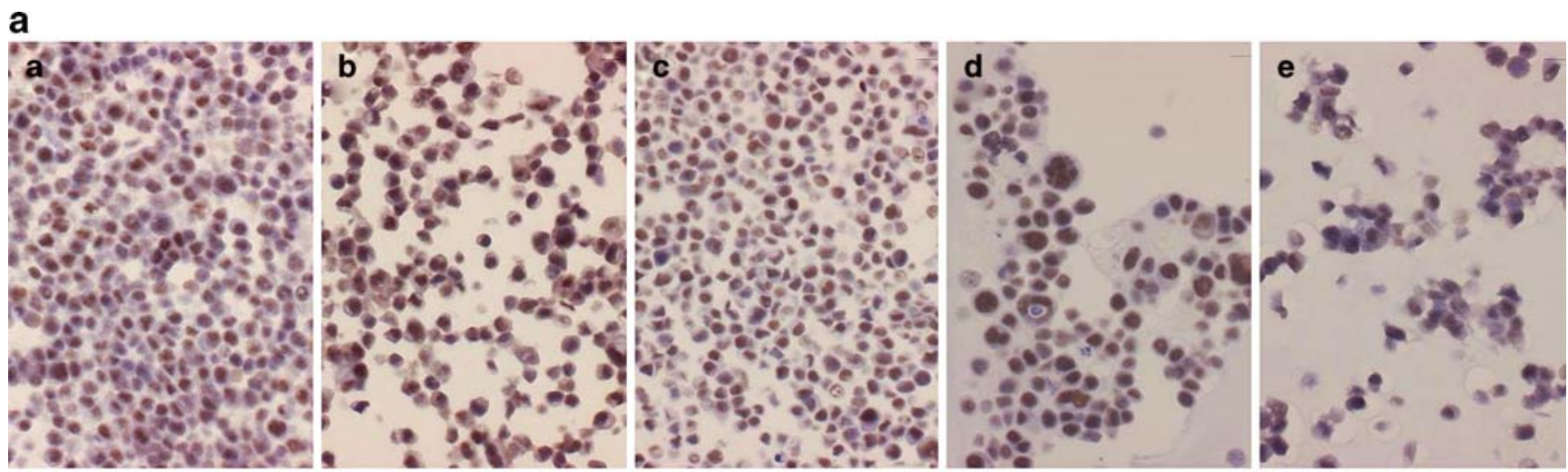

b

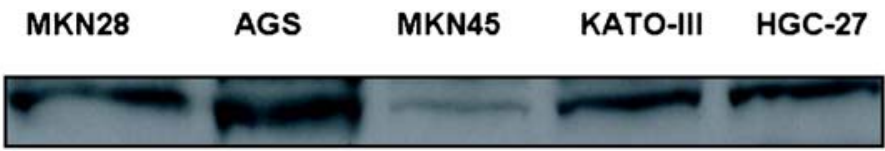

parafibromin

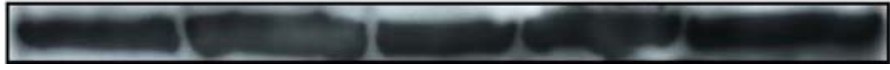

$\beta$-actin

Fig. 1 Parafibromin expression in gastric carcinoma cell lines. a Parafibromin was positively immunostained in the nucleus of MKN28 $(a)$, AGS (b), MKN45 (c), KATO-III (d) and HGC-27(e). b Cell lysate
$(50 \mu \mathrm{g})$ was loaded and probed with anti-human parafibromin antibody $(60 \mathrm{kd})$ with $\beta$-actin $(42 \mathrm{kd})$ as an internal control. Lane \#1: MKN28; \#2 AGS; \#3 MKN45; \#4 KATO-III; \#5 HGC-27
45 adenoma patients $(80.0 \%)$ and 233 out of total 508 gastric carcinoma patients $(45.9 \%)$. Statistically, gradually reduced expression of parafibromin was seen from gastritis to gastric carcinoma through gastric adenoma $(p<0.05$, Table 1). As summarised in Table 2, parafibromin expression was inversely correlated with tumour size, depth of invasion, lymphatic invasion, lymph node metastasis and UICC staging $(p<0.05)$ but not with sex or venous invasion $(p>0.05)$. Parafibromin was strongly expressed in older carcinoma patients compared with younger ones $(p<0.05)$. Intestinal-type carcinomas exhibited more frequent expression of parafibromin than diffuse-type ones $(p<0.05)$.
Fig. 2 Immunohistochemical staining of parafibromin in gastritis, adenoma and carcinoma. Note parafibromin positivity was strongly observed in the nucleus of gastric superficial epithelium (a), and adenoma (c) and early gastric carcinoma (b), occasionally weaker in the stromal fibroblasts and lymphocytes $(\mathbf{a}, \mathbf{c})$, but not in given advanced gastric carcinomas (d), indicating that the internal positive control (stromal cells) was negative adjacent to the negative staining carcinoma cells but positive adjacent to the positive epithelial cells
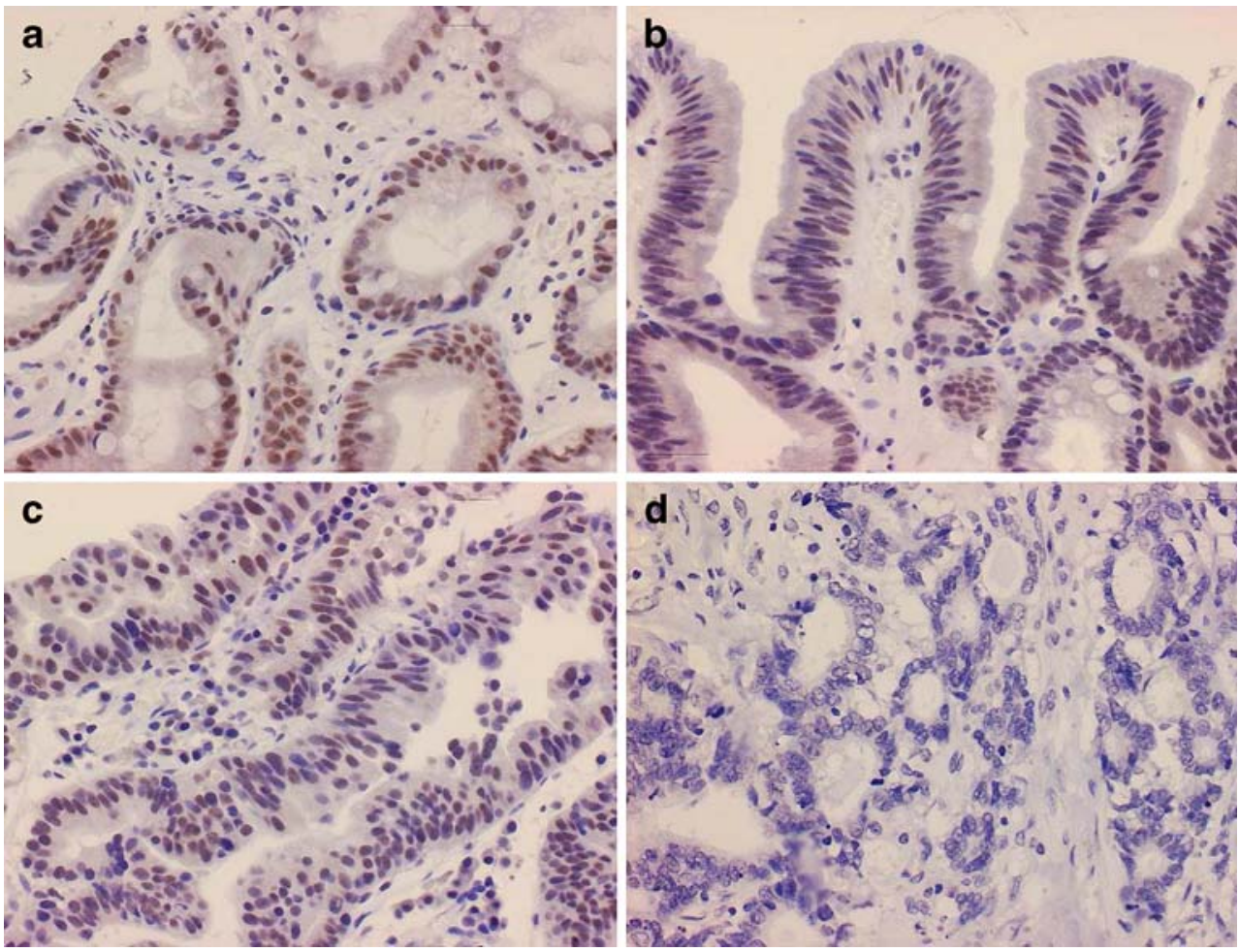
Table 1 Parafibromin expression in gastric tissue samples

\begin{tabular}{|c|c|c|c|c|c|c|}
\hline \multirow[t]{2}{*}{ Groups } & \multirow[t]{2}{*}{ Number } & \multicolumn{5}{|c|}{ Parafibromin expression } \\
\hline & & - & + & ++ & +++ & PR $(\%)$ \\
\hline Gastritis & 49 & 0 & 1 & 7 & 41 & $100.0^{\mathrm{a}}$ \\
\hline Gastric adenoma & 45 & 9 & 5 & 8 & 23 & $80.0^{\mathrm{b}}$ \\
\hline Gastric carcinoma & 508 & 275 & 55 & 60 & 118 & 45.9 \\
\hline
\end{tabular}

$P R$ Positive rate

${ }^{\text {a }}$ Compared with gastric adenoma or carcinoma, $p<0.001$

${ }^{\mathrm{b}}$ Compared with gastric carcinoma, $p<0.001$

Univariate and multivariate survival analysis

Follow-up information was available on 508 gastric carcinoma patients for periods ranging from 0.2 months to 12.2 years (median=67.2 months). Figure 3 showed survival curves stratified according to parafibromin expression for gastric carcinomas. Univariate analysis using the Kaplan-Meier method indicated cumulative survival rate of patients with weak, moderate or strong parafibromin expression to be obviously higher than without its expression $(p<0.05$; Fig. 3a). The significant difference disappeared if stratified according to the depth of invasion (Fig. 3b, c). Multivariate analysis using Cox's proportional hazard model indicated that age, tumour size, depth of invasion, lymphatic invasion, lymph node metastasis, UICC staging and Lauren's classification $(p<0.05)$ but not sex,

Table 2 Relationship between parafibromin expression and clinicopathological features of gastric carcinomas

\begin{tabular}{|c|c|c|c|c|c|c|c|c|}
\hline \multirow[t]{2}{*}{ Clinicopathological features } & \multirow[t]{2}{*}{ Number } & \multicolumn{7}{|c|}{ Parafibromin expression } \\
\hline & & - & + & ++ & +++ & PR $(\%)$ & Rs & $p$ value \\
\hline \multicolumn{9}{|l|}{ Age (years) } \\
\hline$<65$ & 209 & 125 & 24 & 24 & 36 & 40.2 & \multirow[t]{2}{*}{0.095} & \multirow[t]{2}{*}{$<0.05$} \\
\hline$\geq 65$ & 299 & 150 & 31 & 36 & 82 & 49.8 & & \\
\hline \multicolumn{9}{|l|}{ Sex } \\
\hline Male & 354 & 188 & 37 & 38 & 91 & 46.9 & \multirow[t]{2}{*}{0.054} & \multirow[t]{2}{*}{$>0.05$} \\
\hline Female & 154 & 87 & 18 & 22 & 27 & 43.5 & & \\
\hline \multicolumn{9}{|l|}{ Tumour size $(\mathrm{cm})$} \\
\hline$<4$ & 263 & 116 & 26 & 34 & 85 & 55.9 & \multirow[t]{2}{*}{-0.237} & \multirow[t]{2}{*}{$<0.001$} \\
\hline$\geq 4$ & 245 & 159 & 27 & 26 & 33 & 35.1 & & \\
\hline \multicolumn{9}{|l|}{ Depth of invasion } \\
\hline $\mathrm{T}_{\mathrm{is}-1}$ & 263 & 102 & 30 & 40 & 91 & 61.2 & \multirow[t]{2}{*}{-0.344} & \multirow[t]{2}{*}{$<0.001$} \\
\hline $\mathrm{T}_{2-4}$ & 245 & 173 & 25 & 20 & 27 & 29.4 & & \\
\hline \multicolumn{9}{|l|}{ Lymphatic invasion } \\
\hline- & 331 & 157 & 42 & 45 & 87 & 52.6 & \multirow[t]{2}{*}{-0.168} & \multirow[t]{2}{*}{$<0.001$} \\
\hline+ & 177 & 118 & 13 & 15 & 31 & 33.3 & & \\
\hline \multicolumn{9}{|l|}{ Venous invasion } \\
\hline- & 443 & 236 & 49 & 51 & 107 & 46.7 & \multirow[t]{2}{*}{-0.051} & \multirow[t]{2}{*}{$>0.05$} \\
\hline+ & 65 & 39 & 6 & 9 & 11 & 40.0 & & \\
\hline \multicolumn{9}{|l|}{ Lymph node metastasis } \\
\hline- & 317 & 138 & 38 & 44 & 97 & 56.5 & \multirow[t]{2}{*}{-0.285} & \multirow{2}{*}{$<0.001$} \\
\hline+ & 191 & 137 & 17 & 16 & 21 & 28.3 & & \\
\hline \multicolumn{9}{|l|}{ UICC staging } \\
\hline $0-\mathrm{I}$ & 292 & 123 & 36 & 41 & 92 & 57.9 & \multirow[t]{2}{*}{-0.292} & \multirow[t]{2}{*}{$<0.001$} \\
\hline II-IV & 216 & 152 & 19 & 19 & 26 & 29.6 & & \\
\hline \multicolumn{9}{|l|}{ Lauren's classification } \\
\hline Intestinal-type & 273 & 108 & 34 & 38 & 93 & 60.4 & \multirow[t]{2}{*}{-0.322} & \multirow[t]{2}{*}{$<0.001$} \\
\hline Diffuse-type & 225 & 157 & 21 & 22 & 25 & 30.2 & & \\
\hline
\end{tabular}

$P R$ Positive rate, $T_{i s}$ carcinoma in situ, $T_{l}$ lamina propria and submucosa, $T_{2}$ muscularis propria and subserosa, $T_{3}$ exposure to serosa, $T_{4}$ invasion into serosa, UICC Union Internationale Contre le Cancer 

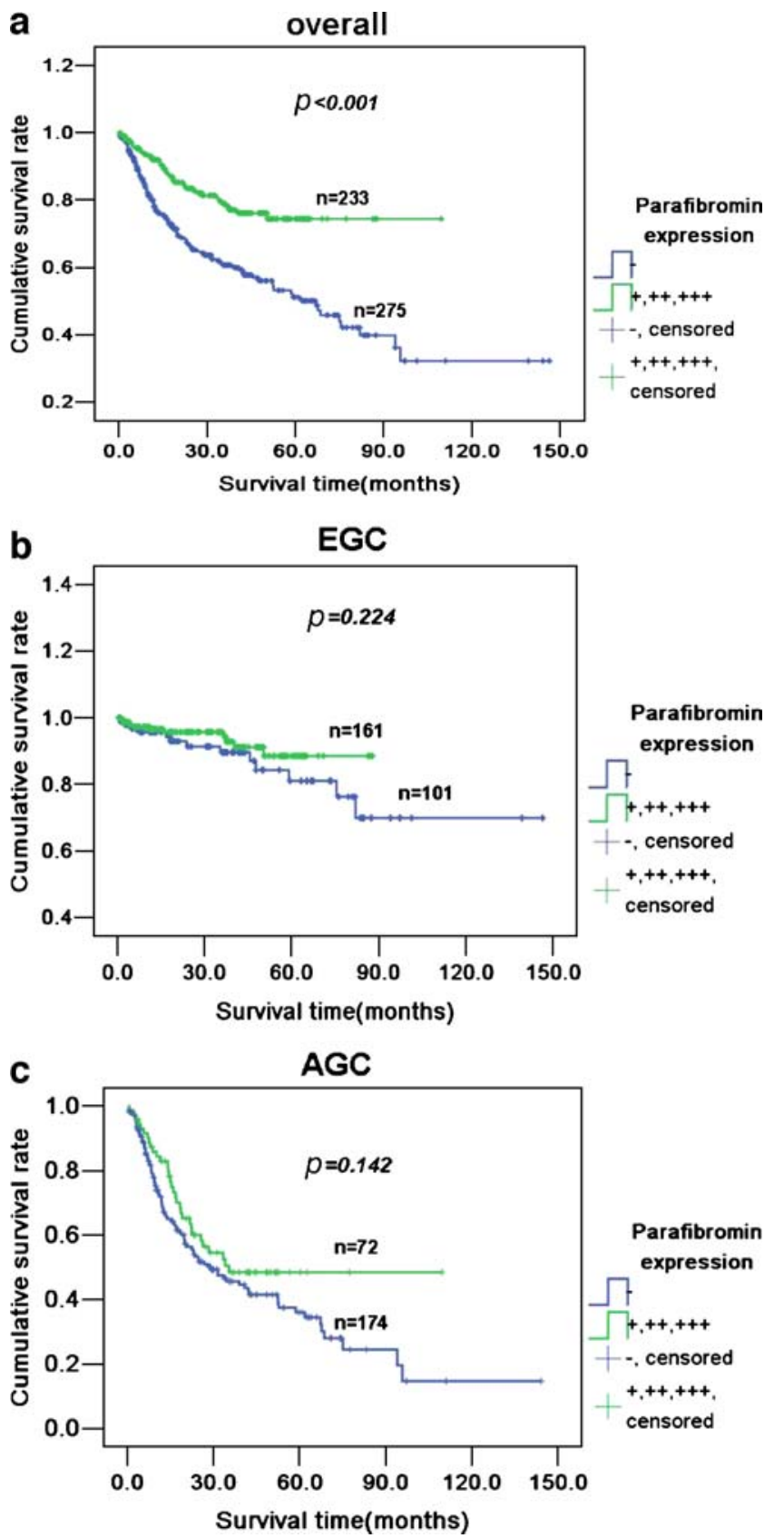

Fig. 3 Correlation between parafibromin status and prognosis of the gastric carcinoma patients. Kaplan-Meier curves for cumulative survival rate of patients with gastric carcinomas according to the parafibromin expression in overall (a), early (b,EGC) and advanced (c, $A G C)$ gastric carcinomas

venous invasion or parafibromin expression were independent prognostic factors for overall gastric carcinomas $(p>0.05$; Table 3$)$.

\section{Discussion}

HRPT2 has been isolated from complementary DNA libraries of parathyroid, kidney and bone tissue and encodes tumour suppressor protein parafibromin [4]. In the present study, the nuclear expression pattern was observed in the gastric epithelial cells, adenomas, adenocarcinomas and carcinoma cell lines consistent with previous reports in the gastric superficial mucosa, hepatocytes, kidney cortex tubules, adrenal gland, spleen lymphocytes, parathyroid tissue, adenoma and carcinomas, breast carcinoma [5, 8, 17, 19]. Although the result was in contrast with the paper of Porzionato et al. [17] possibly due to different incubation times of primary antibody, the great majority of immunohistochemical and cell transfection studies supported our observation of the nuclear staining $[2,5,6,8,14,19]$. This study again demonstrates that parafibromin is nuclear and not cytoplasmic or nucleocytoplasmic in location as initially thought. The weaker expression of parafibromin in stromal cells than epithelial cells and adenoma might be due to the specificity of its cellular distribution as described previously [17]. It was found that the translocation of parafibromin to the nuclear compartment involved a function monopartite nuclear localisation signal at residues 136-139 [2, 6]. Parafibromin is a component of Pafl complex in the nucleus, where it plays a role in cell cycle regulation, histone methylation, lipid and nucleic acid metabolism [10, 17]. The distribution pattern of parafibromin protein in gastric epithelial cells or tumour cells demonstrated its biological function in the nucleus.

Statistically, parafibromin expression was gradually reduced from gastritis to carcinoma through adenoma in line with parathyroid carcinogenesis, suggesting that downregulated parafibromin expression might contribute to the malignant transformation of gastric epithelial cells as an early event. The positive rate of parafibromin expression was reduced to $80 \%$ in gastric adenoma and reached about $46 \%$ of gastric adenocarcinoma, supporting the involvement of parafibromin in the gastric adenoma-adenocarcinoma sequence. Actually, the adenoma can progress into and be incorporated with gastric well-differentiated carcinoma when it grows bigger and de novo carcinogenesis is well understood, especially in diffuse-type gastric carcinomas [34]. Higher parafibromin expression in adenoma and intestinaltype carcinoma indicated that decreased parafibromin expression might play an important role in de novo diffusetype carcinogenesis but less in intestinal carcinogenic pathway.

A body of evidences indicated that downregulation of tumour suppressor protein expression was due to genetic or epigenetic changes, like allelic loss, mutation, loss of heterozygosity (LOH), hypermethylation and microsatellite instability in malignancies $[29,30]$. In the sporadic parathyroid carcinomas and hyperparathyroidism-jaw tumours, LOH or mutation of HRPT2 might cause the loss and inactivation of parafibromin protein [20, 25, 26]. Furthermore, the reduced expression of parafibromin was 
Table 3 Multivariate analysis of clinicopathological variables for survival with gastric carcinomas

\begin{tabular}{llll}
\hline Number & Clinicopathological parametres & Relative risk (95\%CI) & $p$ value \\
\hline A & Age $(\geq 65$ years $)$ & $1.929(1.357-2.743)$ & $<0.001$ \\
B & Sex $($ female) & $1.463(0.983-2.179)$ & $>0.05$ \\
C & Tumour size $(\geq 4 \mathrm{~cm})$ & $1.606(1.013-2.547)$ & $<0.05$ \\
D & Depth of invasion $\left(T_{2-4}\right)$ & $6.530(3.110-13.710)$ & $<0.001$ \\
E & Lymphatic invasion $(+)$ & $2.626(1.516-3.374)$ & $<0.001$ \\
F & Venous invasion $(+)$ & $0.959(0.633-1.452)$ & $<0.05$ \\
G & Lymph node metastasis $(+)$ & $2.773(1.525-5.043)$ & $<0.01$ \\
H & UICC staging (II-IV) & $0.294(0.139-0.622)$ & $<0.01$ \\
I & Lauren's classification $($ diffuse-type) & $1.796(1.212-2.661)$ & $<0.01$ \\
J & Parafibromin expression $(+\sim+++)$ & $0.792(0.529-1.187)$ &
\end{tabular}

$C I$ Confidence interval, $U I C C=$ Union Internationale Contre le Cancer

found to closely link to the tumour size, depth of invasion, lymphatic or venous invasion and UICC staging in line with the observation in breast carcinomas [19], indicating the inhibitory effects of parafibromin on tumour growth, invasion, metastasis and progression of gastric carcinomas. Drosophila Hyrax and its human orthologue, parafibromin, are required for nuclear transduction of the $\mathrm{Wnt} / \mathrm{Wg}$ signal and bind directly to the C-terminal region of beta-cateninArmadillo, thereby controlling transcriptional initiation and elongation by RNA polymerase II [15]. Parafibromin overexpression can inhibit colony formation, anchoragedependent cell growth and cellular proliferation and induce cell cycle arrest in the G1 phase [28]. These findings demonstrated that loss of parafibromin expression had impact on the pathogenesis and progression of malignancies by promoting cellular proliferation. Additionally, parafibromin was expressed with a higher incidence in intestinal-type gastric cancer, which is presumed to arise from preceding dysplastic lesions, than diffuse-type one, which evolves without any precedent dysplastic changes. It is also demonstrated that distinct parafibromin expression underlies the molecular mechanisms for the differentiation of intestinal- and diffuse-type carcinomas.

Until now, there is yet no paper describing the prognostic significance of parafibromin expression in malignancies. Here, for the first time, we analysed the relation of parafibromin expression with the survival rate of 508 patients with gastric carcinoma. The results revealed a close link between its loss and worse survival. If stratified according to the depth of invasion, the significant link disappeared, indicating that the relationship between parafibromin expression and prognosis depends on the depth of invasion. The multivariate analysis demonstrated that age, depth of invasion, lymphatic invasion, lymph node metastasis, UICC staging and Lauren's classification but not parafibromin expression, venous invasion or sex were independent prognostic factors for carcinomas. These findings suggested that parafibromin expression is a promising indicator for the favorable prognosis of gastric carcinoma patients, albeit not independent.

In the present study, a large number of gastric carcinoma cases were screened by TMA, which takes the advantages of high throughput, identical immunohistochemical conditions, and economy of samples, antibodies and time [33]. Although we used 2-mm-in-diametre needles, which are large enough to evaluate the morphological appearance and carefully selected representative regions with the reference of HE slides, it was difficult to avoid selection bias. Gill et al. [5] found that stronger parafibromin staining and more positive cells sometimes appeared at the edges of the parathyroid tumour than in the centre. This could be due to fixation methods, other processing issues or a biological phenomenon, for example tissue hypoxia in the centre of large tumours. Additionally, the collection of our samples (e.g. gastritis, adenoma and adenocarcinoma) respectively from the endoscopic biopsy, polypectomy, or surgical resection put forward their another possibility of selection bias because of different fixation and processing methods. Selvarajan et al. [19] found that parafibromin underexpression was correlated particularly with large tumour size which is in line with our finding. It was possible that weaker staining could be attributable to poor fixation properties in the centre of large tumours. Because tumour size is a key prognostic indicator, this artifact could explain the prognostic significance of parafibromin in gastric carcinomas. Therefore, it is a limitation of the present study not to separate the edge and centre of gastric carcinomas when establishing TMA. In the current study, the negatively staining carcinomas are associated with a negative internal control (stromal cells and lymphocytes) whereas the positive staining epithelium is adjacent to positive staining internal controls. Therefore, the negative staining of the carcinoma might be artificial, which should be considered as another limitation of the study. Our study might be mentioned as a preliminary experiment and the staining with original-size sections is an extensive work in 
the future using the gastric carcinoma samples, fixed and processed by the same approach.

In summary, downregulated parafibromin expression might play an important role in malignant transformation of gastric epithelial cells. Its reduced expression was closely related to growth, invasion, metastasis and worse prognosis of gastric carcinomas. Its expression could be employed to differentiate the intestinal- and diffuse-type carcinomas and underlay the molecular mechanism about the differentiation of both carcinomas. It was considered as a promising marker to indicate the pathobiological behaviours and prognosis of gastric carcinomas.

Acknowledgements We particularly thanked Kanako Yasuyoshi, Tokimasa Kumada and Hideki Hatta for their technical help and Yukari Inoue for her secretarial assistance. This work was partially supported by the Japanese Ministry of Education, Science, Sports and Culture, Grant-in-Aid for Scientific Research 14770072, Japanese Smoking Foundation and Shenyang Outstanding Scholar Foundation.

Conflict of interest statement No conflict of interest

\section{References}

1. Aldred MJ, Talacko AA, Savarirayan R, Murdolo V, Mills AE, Radden BG, Alimov A, Villablanca A, Larsson C (2006) Dental findings in a family with hyperparathyroidism-jaw tumour syndrome and a novel HRPT2 gene mutation. Oral Surg Oral Med Oral Pathol Oral Radiol Endod 101:212-218

2. Bradley KJ, Bowl MR, Williams SE, Ahmad BN, Partridge CJ, Patmanidi AL, Kennedy AM, Loh NY, Thakker RV (2007) Parafibromin is a nuclear protein with a functional monopartite nuclear localization signal. Oncogene 26:1213-1221

3. Bradley KJ, Cavaco BM, Bowl MR, Harding B, Young A, Thakker RV (2005) Utilisation of a cryptic non-canonical donor splice site of the gene encoding PARAFIBROMIN is associated with familial isolated primary hyperparathyroidism. J Med Genet 42:e51

4. Carpten JD, Robbins CM, Villablanca A, Forsberg L, Presciuttini S, Bailey-Wilson J, Simonds WF, Gillanders EM, Kennedy AM, Chen JD, Agarwal SK, Sood R, Jones MP, Moses TY, Haven C, Petillo D, Leotlela PD, Harding B, Cameron D, Pannett AA, Hoog A, Heath H, James-Newton LA, Robinson B, Zarbo RJ, Cavaco BM, Wassif W, Perrier ND, Rosen IB, Kristoffersson U, Turnpenny PD, Farnebo LO, Besser GM, Jackson CE, Morreau H, Trent JM, Thakker RV, Marx SJ, Teh BT, Larsson C, Hobbs MR (2002) HRPT2, encoding parafibromin, is mutated in hyperparathyroidism-jaw tumour syndrome. Nat Genet 32:676-680

5. Gill AJ, Clarkson A, Gimm O, Keil J, Dralle H, Howell VM, Marsh DJ (2006) Loss of nuclear expression of parafibromin distinguishes parathyroid carcinomas and hyperparathyroidism - jaw tumour (HPT-JT) syndrome-related adenomas from sporadic parathyroid adenomas and hyperplasias. Am J Surg Pathol 30:1140-1149

6. Hahn MA, Marsh DJ (2005) Identification of a functional bipartite nuclear localization signal in the tumour suppressor parafibromin. Oncogene 24:6241-6248

7. Howell VM, Haven CJ, Kahnoski K, Khoo SK, Petillo D, Chen J, Fleuren GJ, Robinson BG, Delbridge LW, Philips J, Nelson AE, Krause U, Hammje K, Dralle H, Hoang-Vu C, Gimm O, Marsh
DJ, Morreau H, Teh BT (2003) HRPT2 mutations are associated with malignancy in sporadic parathyroid tumours. J Med Genet 40:657-663

8. Juhlin C, Larsson C, Yakoleva T, Leibiger I, Leibiger B, Alimov A, Weber G, Hoog A, Villablanca A (2006) Loss of parafibromin expression in a subset of parathyroid adenomas. Endocr Relat Cancer 13:509-523

9. Kelley JR, Duggan JM (2003) Gastric cancer epidemiology and risk factors. J Clin Epidemiol 56:1-9

10. Krogan NJ, Dover J, Wood A, Schneider J, Heidt J, Boateng MA, Dean K, Ryan OW, Golshani A, Johnston M, Greenblatt JF, Shilatifard A (2003) The Pafl complex is required for histone H3 methylation by COMPASS and Dotlp: linking transcriptional elongation to histone methylation. Mol Cell 11:721-729

11. Kumada T, Tsuneyama K, Hatta H, Ishizawa S, Takano Y (2004) Improved 1-h rapid immunostaining method using intermittent microwave irradiation: practicability based on 5 years application in Toyama Medical and Pharmaceutical University Hospital. Mod Pathol 17:1141-1149

12. Kurokawa T, Fuchigami A (1967) Gastric carcinoma in its early stages. Naika 20:824-829

13. Lauren $P$ (1965) The two histological main types of gastric carcinoma: diffuse and so-called intestinal-type carcinoma. An attempt at a histo-clinical classification. Acta Pathol Microbiol Scand 64:31-49

14. Lin L, Czapiga M, Nini L, Zhang JH, Simonds WF (2007) Nuclear localization of the parafibromin tumor suppressor protein implicated in the hyperparathyroidism-jaw tumor syndrome enhances its proapoptotic function. Mol Cancer Res 5:183-193

15. Mosimann C, Hausmann G, Basler K (2006) Parafibromin/hyrax activates $\mathrm{Wnt} / \mathrm{Wg}$ target gene transcription by direct association with beta-catenin/Armadillo. Cell 125:327-341

16. Pimenta FJ, Gontijo Silveira LF, Tavares GC, Silva AC, Perdigao PF, Castro WH, Gomez MV, Teh BT, De Marco L, Gomez RS (2006) HRPT2 gene alterations in ossifying fibroma of the jaws. Oral Oncol 42:735-739

17. Porzionato A, Macchi V, Barzon L, Masi G, Iacobone M, Parenti A, Palu G, De Caro R (2006) Immunohistochemical assessment of parafibromin in mouse and human tissues. J Anat 209:817-827

18. Rozenblatt-Rosen O, Hughes CM, Nannepaga SJ, Shanmugam KS, Copeland TD, Guszczynski T, Resau JH, Meyerson M (2005) The parafibromin tumour suppressor protein is part of a human Pafl complex. Mol Cell Biol 25:612-620

19. Selvarajan S, Sii LH, Lee A, Yip G, Bay BH, Tan MH, Teh BT, Tan PH (2007) Parafibromin expression in breast cancer: a novel marker for prognostication? J Clin Pathol (in press)

20. Shattuck TM, Valimaki S, Obara T, Gaz RD, Clark OH, Shoback D, Wierman ME, Tojo K, Robbins CM, Carpten JD, Farnebo LO, Larsson C, Arnold A (2003) Somatic and germ-line mutations of the HRPT2 gene in sporadic parathyroid carcinoma. N Engl J Med 349:1722-1729

21. Sobin LH, Wittekind CH (2002) TNM classification of malignant tumours, 6th edn. Wiley, Hoboken

22. Tan MH, Morrison C, Wang P, Yang X, Haven CJ, Zhang C, Zhao P, Tretiakova MS, Korpi-Hyovalti E, Burgess JR, Soo KC, Cheah WK, Cao B, Resau J, Morreau H, Teh BT (2004) Loss of parafibromin immunoreactivity is a distinguishing feature of parathyroid carcinoma. Clin Cancer Res 10:6629-6637

23. Wang PF, Tan MH, Zhang C, Morreau H, Teh BT (2005) HRPT2, a tumour suppressor gene for hyperparathyroidism-jaw tumour syndrome. Horm Metab Res 37:380-383

24. Wood A, Krogan NJ, Dover J, Schneider J, Heidt J, Boateng MA, Dean K, Golshani A, Zhang Y, Greenblatt JF, Johnston M, Shilatifard A (2003) Bre1, an E3 ubiquitin ligase required for recruitment and substrate selection of Rad6 at a promoter. Mol Cell 11:267-274 
25. Woodard GE, Lin L, Zhang JH, Agarwal SK, Marx SJ, Simonds WF (2005) Parafibromin, product of the hyperparathyroidism-jaw tumour syndrome gene HRPT2, regulates cyclin D1/PRAD1 expression. Oncogene 24:1272-1276

26. Yang GY, Zhang YC, Liu XD, Wu YQ, Li MS, Gong CY, Guan BW, Mi DH, Liu S (1992) Geographic pathology on the precursors of stomach cancer. J Environ Pathol Toxicol Oncol 11: 339-344

27. Yart A, Gstaiger M, Wirbelauer C, Pecnik M, Anastasiou D, Hess D, Krek W (2005) The HRPT2 tumour suppressor gene product parafibromin associates with human PAF1 and RNA polymerase II. Mol Cell Biol 25:5052-5060

28. Zhang C, Kong D, Tan MH, Pappas DL, Wang PF, Chen J, Farber L, Zhang N, Koo HM, Weinreich M, Williams BO, Teh BT (2006) Parafibromin inhibits cancer cell growth and causes G1 phase arrest. Biochem Biophys Res Commun 350:17-24

29. Zheng HC, Sun JM, Li XH, Yang XF, Zhang YC, Xin Y (2003) Role of PTEN and MMP-7 expression in growth, invasion, metastasis and angiogenesis of gastric carcinoma. Pathol Int 53: 659-666

30. Zheng H, Takahashi H, Murai Y, Cui Z, Nomoto K, Niwa H, Tsuneyama K, Takano Y Low expression of FHIT and PTEN correlates with malignancy of gastric carcinomas. Appl Immunohistochem Mol Morphol (in press)

31. Zheng H, Takahashi H, Murai Y, Cui Z, Nomoto K, Miwa S, Tsuneyama K, Takano Y (2007) Pathobiological characteristics of intestinal and diffuse-type gastric carcinoma in Japan: an immunostaining study on the tissue microarray. J Clin Pathol 60:273-277

32. Zheng HC, Takahashi H, Murai Y, Cui ZG, Nomoto K, Miwa S, Tsuneyama K, Takano Y (2006) Upregulated EMMPRIN/CD147 might contribute to growth and angiogenesis of gastric carcinoma: a good marker for local invasion and prognosis. $\mathrm{Br} \mathrm{J}$ Cancer 95:1371-1378

33. Zheng H, Takahashi H, Nakajima T, Murai Y, Cui Z, Nomoto K, Tsuneyama K, Takano Y (2006) MUC6 down-regulation correlates with gastric carcinoma progression and a poor prognosis: an immunohistochemical study with tissue microarrays. J Cancer Res Clin Oncol 132:817-823

34. Zheng HC, Tsuneyama K, Takahashi H, Miwa S, Sugiyama T, Popivanova BK, Fujii C, Nomoto K, Mukaida N, Takano Y (2007) Aberrant Pim-3 expression is involved in gastric adenomaadenocarcinoma sequence and cancer progression. J Cancer Res Clin Oncol (in press) 